\title{
NICKEL-BASED ALLOY DRY MILLING FORCE AND TEMPERATURE BY USING MONOLITHIC CERAMIC END MILL TOOL
}

\author{
Z. Yuan ${ }^{1}$, J. Zha ${ }^{1 *}$, J. Liang ${ }^{1}$, Y. Li ${ }^{1}$, Y. Chen ${ }^{1}$ \\ ${ }^{1}$ Xi'an Jiaotong University, School of Mechanical Engineering, Xi'an, China \\ *Corresponding author; e-mail: jun_zha@xjtu.edu.cn
}

\begin{abstract}
Nickel-based alloys are known to be difficult to cut material, which can cause high cutting forces and temperature rise which always lead to excessive tool wear. Traditional views hold the opinion that cutting temperature rise could lead to negative effects. However, milling under high temperature, cutting material can get a thermal softening effect. In this research, the monolithic ceramic end mill was used. By using high temperature generated at shear zone, nickel-based alloy can be easily cut and achieved a high material removal rate. The experiment result shows, with the rise of cutting speed, cutting forces can be reduced.
\end{abstract}

\section{Keywords:}

Nickel-based alloy; Monolithic ceramic end mill; High speed milling; Material removal rate

\section{INTRODUCTION}

Nickel-based alloy are widely used in aeronautical engine components and gas turbine engines because it has excellent mechanical character and good resistant to oxidation when operating under high temperature conditions. However, nickel-based alloys are hard to cut material, and its poor machinability has already been summarized [Ezugwu 1998]. The seven reasons are due to the strength of nickel-based alloy is maintained during machining, the existence of work hardening as well as low thermal diffusivity when machining, low thermal diffusivity can leads to cutting tool suffering from abrasive, chemical reaction, welding or adhesion of workpiece material and cutting process always produce a tough and continuous chip that makes nickel-based alloy a difficult problem for machining.

If the temperature induced material soften phenomenon used in machining, it can make these hard to cut material become easy to cut [Sun 2010]. Through laser assisted machining (LAM), nickel-based alloy can be easily cut. [Leopardi G 2015] LAM is widely used in rough machining process. By using external heat sources mounted in front of cutting tool, the temperature in cutting region can increase at a short time which reduces both tensile strength and yield strength of cutting materials that makes hard to machine materials be easily cut during machining process. However, the radiation of laser can also cause tool wear and short tool life.

During machining process, most of the mechanical work are converted into thermal energy. Although most of heat is dissipated by chip, generally approximately $50 \%$ of mechanical energy still converted into heat in the shear zone. In high speed machining Inconel alloys, cutting tool withstand higher cutting force than cutting common materials, which can make cutting region an increase in temperature. [Altintas $Y$ 2012] Cutting speed has the greatest influence on the maximum cutting temperatures. When cutting speed rises, temperature at the shear zone also rise [Klocke 2011]. Kitagawa etc. found that by using TiC added alumina ceramic tool, the Inconel 718 alloy cutting temperature can exceeds $1200^{\circ} \mathrm{C}$ at rake face [Kitagawa 1997]. High temperature can cause severe tool wear. [Xavior M A 2017] Tool wear can be classified into thermo-dynamic wear, thermo-chemical wear, oxidation, adhesion and diffusion of cutting tool. By using carbide tools, major tool wear is abrasive wear. [Zhang 2012] High temperature induced chemical wear is also a very serious problem, such as chemical affinity of both tool material and workpiece material [Zhu 2013]. Ceramic have good resistant to heat, taking Silicon and SiAION ceramics as an example, these ceramics are fabricated at about $1700^{\circ} \mathrm{C}$, most common phase formation of SiAION ceramics are at $1600-1700^{\circ} \mathrm{C}$. Therefore, for most kind of SiAION ceramics, it is unstable at above $1600^{\circ} \mathrm{C}$. [Obikawa T 2015] It also has high strength and toughness, good wear resistance and excellence in thermal shock resistance [Izhevskiy 2000] [Komanduri 1988].

All the studies above provide a background for the benefit that temperature increment can make nickel-based alloy be easily cut. By using ceramic tool, cutting temperature seems having less influence on tool wear. If temperature in the cutting region get enough high, when shear zone temperature reaches the tensile strength turning point or higher of hard to cut materials, according to temperature induced material soften phenomenon, cutting force can get a reduction.

This research mainly focuses on milling effects and determines the benefits that using monolithic ceramic milling tool for dry machining nickel-based alloy as well as gaining a broader understanding for dry milling temperature 
in the cutting zone caused reduction in cutting force, then analysis the milling parameter induced force reduction and material removal rate (MRR) in milling nickel-based alloy. By using finite element method analysis (FEM), a broader understanding of cutting speed, cutting width caused temperature increment in the shear zone was obtained. Then, through orthogonal experiment conduction, the FEM simulation results was verified. According to the experiment and simulation results, the milling parameter was determined on force reduction. For instance, a selected milling parameter result was concluded. According to the wear analysis for monolithic milling tool, the wear mechanism of dry milling nickel-based alloy through ceramic tools can be briefly summarized.

\section{SIMULATION}

\subsection{Material mode}

The milling process was simulated by AdvantEdge software, workpiece was set to be nickel alloy ÉK-61 (KhN58MBYuD) and milling tool was SiAION ceramics. Workpiece used the elastic-plastic model. Nickel-based alloy ÉK-61(KhN58MBYuD) chemical composition is shown in table 1. The mechanical properties of ÉK61(KhN58MBYuD) are shown in table 2. [Evek Corp 2018] In order to make simulation process more precise, the workpiece material used custom defined constitutive model. [Maurel-Pantel A 2012] The model can be expressed as following equation:

$$
\sigma\left(\varepsilon^{p}, \dot{\varepsilon}, \mathrm{T}\right)=\mathrm{g}\left(\varepsilon^{p}\right) \times \Gamma(\dot{\varepsilon}) \times \Theta(\mathrm{T})
$$

$\mathrm{g}\left(\varepsilon^{p}\right)$ Represents Strain Hardening, $\Gamma(\dot{\varepsilon})$ is strain Rate Sensitivity and $\Theta(T)$ is Thermal Softening parameter [Thirdwave Systems 2007].

\subsection{Simulation results}

The simulated milling process were set to be threedimensional up milling process. Milling tool used solid tool model and milling model was side milling model. Cutting parameters and the milling tool parameters are listed in table 3. The milling tool parameters are referred to monolithic ceramic end mill tool of Kennametal Inc. [Davis 2014].

From the milling simulation, workpiece temperature fields can be seen from figure 1, cutter temperature thermal temperature field can be seen from figure 2. As the picture shown milling temperature can reach the highest point to about $1221^{\circ} \mathrm{C}$. The average cutting temperature in the shear zone can reach about $800-1000^{\circ} \mathrm{C}$. The milling tool cutter edge contacted with the workpiece material temperature can reach to $900-1000^{\circ} \mathrm{C}$.

Through simulated milling force in $\mathrm{X}, \mathrm{Y}, \mathrm{Z}$ directions, figure 3 was obtained, three different milling force variation through the change of angular length of cut.
The average temperature in the cutter and workpiece contact zone has already reached workpiece tensile strength turning point. It can be concluded that material soften phenomenon has happened in the dry milling process.

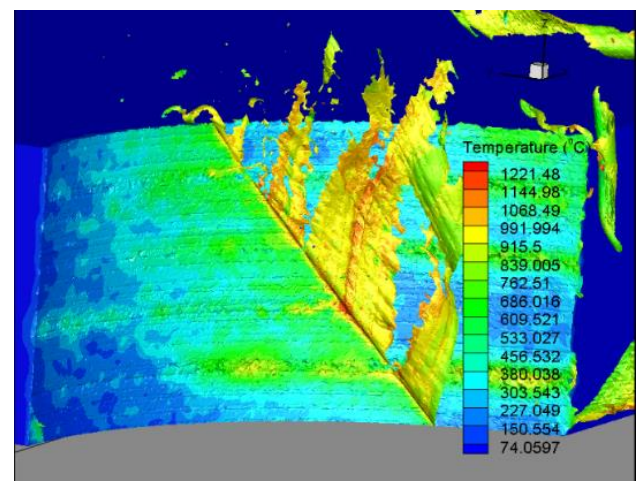

Fig. 1: Workpiece thermal map.

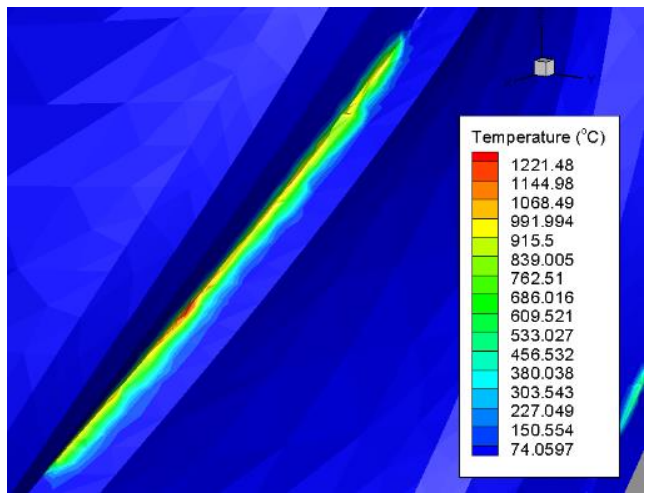

Fig. 2: Milling cutter thermal map.

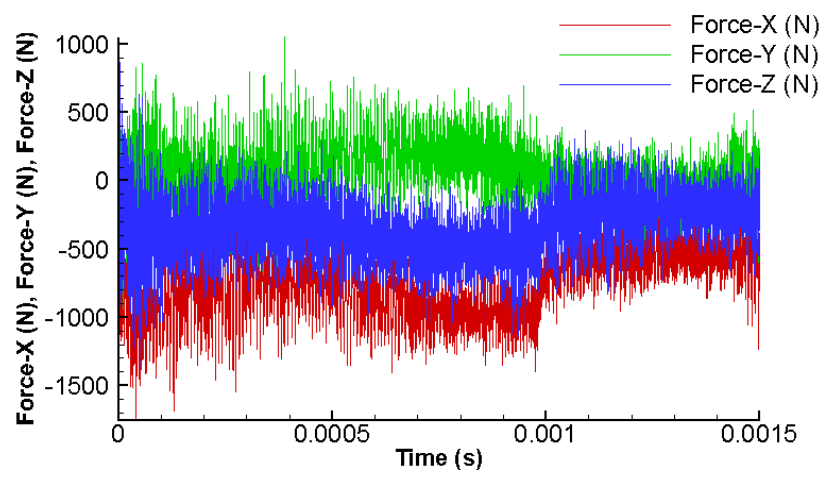

Fig. 3: Milling forces in $X, Y, Z$ direction.

Tab. 1: ÉK-61 chemical composition.

\begin{tabular}{llllllllllllllllllll}
\hline Elements & $\mathrm{C}$ & $\mathrm{S}$ & $\mathrm{P}$ & $\mathrm{Mn}$ & $\mathrm{Cr}$ & $\mathrm{Si}$ & $\mathrm{Ni}$ & $\mathrm{Fe}$ & $\mathrm{Cu}$ & $\mathrm{Al}$ & $\mathrm{V}$ & $\mathrm{Ti}$ & $\mathrm{M}$ & $\mathrm{N}$ & $\mathrm{Ce}$ & $\mathrm{Zr}$ & $\mathrm{La}$ \\
$\mathrm{b}$ & & & & & & & & & & & & & 0 & & \\
\hline Composition & $\leq 0$ & $\leq 0$. & $\leq 0.0$ & $\leq 0$ & 14.5 & $\leq 0$ & $\mathrm{re}$ & $12-$ & 0.1 & 0.5 & 0.3 & 0.2 & $3-$ & $4-$ & 0.0 & $\leq 0$. & 0.0 \\
& .0 & 01 & 15 & 7 & - & .5 & st & 16 & -1 & - & - & -1 & 5 & 5. & 2 & 1 & 1 \\
& 5 & 5 & & & 18.5 & & & & & 1.3 & 0.6 & & & 5 & & & \\
\hline
\end{tabular}


Tab. 2: ÉK-61 mechanical properties.

\begin{tabular}{cc}
\hline Parameters & Value \\
\hline Yield strength $(\sigma 0.2, \mathrm{MPa})$ & $\geq 900$ \\
Limit short-term strength $(\sigma \mathrm{U}, \mathrm{MPa})$ & $\geq 1200$ \\
Elongation after rupture $\left(\mathrm{d}_{5}, \%\right)$ & $\geq 20$ \\
Toughness $\left(\mathrm{KCU}, \mathrm{kJ} / \mathrm{m}^{2}\right)$ & $\geq 490$ \\
\hline
\end{tabular}

Tab. 3: Milling simulation parameters and Milling tool parameters.

\begin{tabular}{cc}
\hline Parameters & Value \\
\hline Spindle speed & $10000 \mathrm{rpm}$ \\
Feed per tooth & $0.03 \mathrm{~mm} /$ tooth. \\
Radical width of cut & $5 \mathrm{~mm}$ \\
Initial temperature & $20^{\circ} \mathrm{C}$ \\
Cutter diameter & $12 \mathrm{~mm}$ \\
Core diameter & $9.02 \mathrm{~mm}$ \\
Number of flutes & 6 \\
Radial rake (tangential degrees) & $-2^{\circ}$ \\
Helical angle & $40^{\circ}$ \\
Radial primary relief angle & $8^{\circ}$ \\
Axial primary land & $0.71 \mathrm{~mm}$ \\
\hline
\end{tabular}

Tab. 4: Orthogonal experiment parameters.

\begin{tabular}{ccccc}
\hline $\begin{array}{c}\text { Experiment } \\
\text { number }\end{array}$ & $\begin{array}{c}\text { Spindle speed } \\
(\mathbf{r p m})\end{array}$ & $\begin{array}{c}\text { Width of cut } \\
(\mathbf{m m})\end{array}$ & $\begin{array}{c}\text { Depth of cut } \\
(\mathbf{m m})\end{array}$ & $\begin{array}{c}\text { Material removal } \\
\text { rate }\left(\mathbf{m m} \mathbf{m}^{\mathbf{m}} \mathbf{m i n}\right)\end{array}$ \\
\hline 1 & 11000 & 5 & 0.3 & 2970 \\
2 & 11000 & 6 & 0.1 & 1188 \\
3 & 11000 & 7 & 0.5 & 6930 \\
4 & 14000 & 6 & 0.3 & 4536 \\
5 & 14000 & 7 & 0.1 & 1764 \\
6 & 14000 & 5 & 0.5 & 6300 \\
7 & 16000 & 7 & 0.3 & 6048 \\
8 & 16000 & 5 & 0.1 & 1440 \\
9 & 16000 & 6 & 0.5 & 8640 \\
\hline
\end{tabular}

\section{EXPERIMMENTS}

An overview of using monolithic ceramic end mill tool of dry milling nickel-based alloy ÉK-61 can be got through simulation. Milling temperature and milling force are both simulated. In order to evaluate the simulation process and know the effects of using monolithic ceramic end mill dry milling nickel-based alloy process, the following $\mathrm{L}_{9}\left(3^{3}\right)$ orthogonal experiment was designed to make a thorough understanding of the effect that using monolithic end mill tool machining nickel-based alloy as well as evaluating the milling efficiency for the purpose of increase milling productivity.

\subsection{Orthogonal experiment design}

The $L_{g}\left(3^{3}\right)$ orthogonal experiment parameters were designed as following table 5 . By determine the spindle speed, cutting width and cutting depth of three different parameters influencing cutting force, a broader view of using monolithic ceramic end mill tool milling nickel-based alloy can be got. The milling cutter is Kennametal EADE KYS40. The cutter material is SiAION with diameterand feed per tooth $0.03 \mathrm{~mm} / \mathrm{z}$.

Spindle speed influences the milling tool milling speed, which has the greatest influence on maximum temperature rise in the contact zone between chip and tool [Klocke 2011]. By increasing the spindle speed, milling temperature in the contact zone increased at the same time, which easily reached the workpiece tensile strength turning point. Through using $12 \mathrm{~mm}$ diameter milling cutter, cutting 
velocity can reach $414 \mathrm{~m} / \mathrm{min}, 528 \mathrm{~m} / \mathrm{min}$ and $603 \mathrm{~m} / \mathrm{min}$ respectively. For nickel-based alloy, these cutting speeds have already been in high speed machining area [Schulz 1992].

Other experiment parameters are set to be high in width of cut and low in depth of cut. The purpose of the setting is trying to make workpiece material removal rate (MRR) stay at a constant high value and increasing milling temperature as well as making milling force not higher.

In the milling process, MRR is determined by axial depth of cut $a_{p}$, width of cut $a_{e}$, spindle speed $n$, feed per tooth $f_{z}$ and the number of cutter teeth $N$. The following equation is the material removal rate equation [Budak 2005].

$$
\mathrm{MRR}=\mathrm{a}_{P} \times a_{e} \times n \times f_{z} \times N
$$

The orthogonal experiment milling material removal rates also listed in table 4.

Orthogonal experiment parameters were conducted through both up milling and down milling for the purpose of making further investigation on the difference of milling force. After experiment process, the wear of monolithic ceramic end milling tool was also detected through scanning electron microscopy.

\subsection{The experiment set-up}

As figure 4 shows, orthogonal milling experiments were conducted on DMG HSC75 5-axis machine. Milling force was detected by Kistler 9265B dynamometer mounted on the self-designed jig. Through the milling experiment process, dynamometer continuous measuring $F_{X}, F_{Y}, F_{Z}$ three-dimensional milling force.

The average force is calculated by equation (3).

$$
F_{\text {ave }}=\sqrt{{F_{x}}^{2}+{F_{y}}^{2}+F_{z}^{2}}
$$

In orthogonal experiments, workpiece material is ÉK-61. Along with milling process, milling force are measured and milling temperature thermal map was captured by FLIR T640 $45^{\circ}$ infrared camera. Infrared camera was mounted on the tripod, which can get a rough view of temperature distribution in milling process.

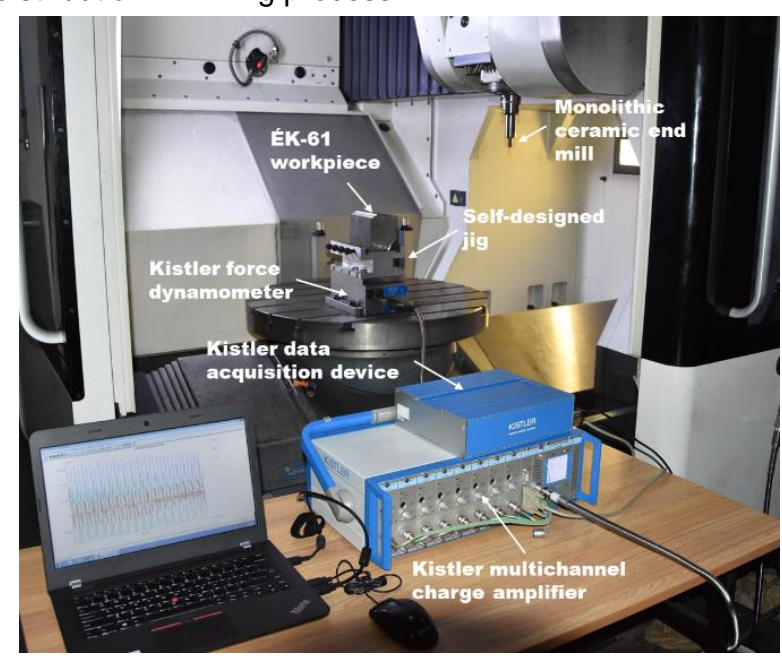

Fig. 4: Orthogonal experiment set-up.

\section{EXPERIMENT RESULTS AND DISCUSSION}

As figure 5 shows, orthogonal experiment process was conducted as dry milling process. Through orthogonal experiments, 9 sets of both up and down milling force data was obtained. Tool wear was examined through SEM and chemical elements were analyzed through EDS to get a rough understanding of milling tool wear.
In orthogonal experiments, variance analysis method is commonly used for experiment data analysis, because of the experiment was an investigation of more than one different parameter induced experiment result, when analyzing acquired experiment force results, intuitive method [Liu 2005] was also used in orthogonal experiment.

After the milling experiment process, 9 sets of milling force data were acquired as following table 6 shows.

As figure 6 shows, thermal map was captured by infrared camera. The temperature field captured through the thermal camera has reached $1191.9^{\circ} \mathrm{C}$. When considering heat dissipate into the air and chip, the temperature field simulation result and experiment acquired temperature field result was roughly the same.

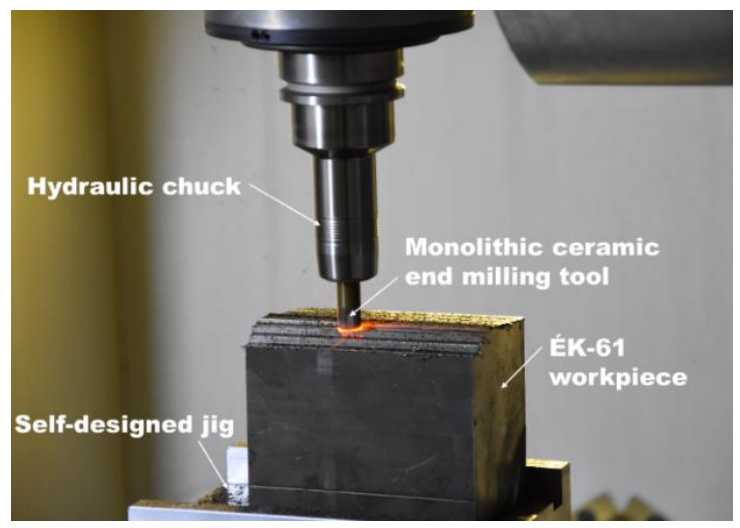

Fig. 5: Image of dry milling experiment process.

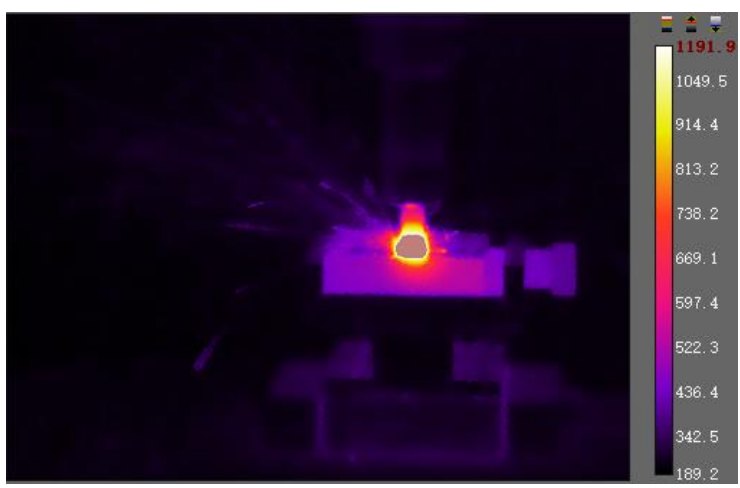

Fig. 6: Temperature field of dry milling process.

Tab. 5: Orthogonal experiment force data.

\begin{tabular}{ccc}
\hline $\begin{array}{c}\text { Experiment } \\
\text { number }\end{array}$ & $\begin{array}{c}\text { Average force in } \\
\text { up milling (N) }\end{array}$ & $\begin{array}{c}\text { Average force in } \\
\text { down milling (N) }\end{array}$ \\
\hline 1 & 458.12 & 481.12 \\
2 & 356.76 & 430.93 \\
3 & 548.28 & 530.52 \\
4 & 287.56 & 434.64 \\
5 & 400.74 & 449.39 \\
6 & 462.50 & 450.35 \\
7 & 385.85 & 396.96 \\
8 & 381.26 & 369.10 \\
9 & 297.20 & 346.36 \\
\hline
\end{tabular}

\subsection{Milling force results intuitive analysis}

According to the force data acquired in experiment, three optimal factors were first selected to determine which combination of factors can cause the best result. Then 
these factors in to an optimal combination for milling force were combined.

In this orthogonal experiment, three different parameters were contained and each parameter has three values. By adding the same value of one parameter in the acquired force data result, one parameter induced milling force result could be got and at the same time other two parameters deviation in experiment procedure could be eliminated. And difference between values can be compared.

Considering different factors, by using equation (4) three different parameters induced milling force could be conducted as one parameter value induced milling force. [Liu 2005] $T_{N F}$ represents the same parameter and same value results added together in experiment. $\mathrm{N}$ ranges from 1 to $3, \mathrm{~F}$ means parameter factor, there are three parameters in this experiment, which are $S$ (spindle speed), W (width of cut) and D (depth of cut). So, $T_{1 S}$ means the sum of the first spindle speed milling force value. And $T_{F 1}$, $T_{F 2}, T_{F 3}$ means they are the same parameter induced three different force value respectively.

$$
T_{N F}=T_{F 1}+T_{F 2}+T_{F 3}
$$

Average milling force data for each parameter is

$$
\bar{T}_{N F}=\frac{T_{N F}}{3}
$$

By subtracting the maximum average milling force and minimum average milling force, milling force range value can be acquired. Through equation (4) and equation (5), the table 6 could be got.

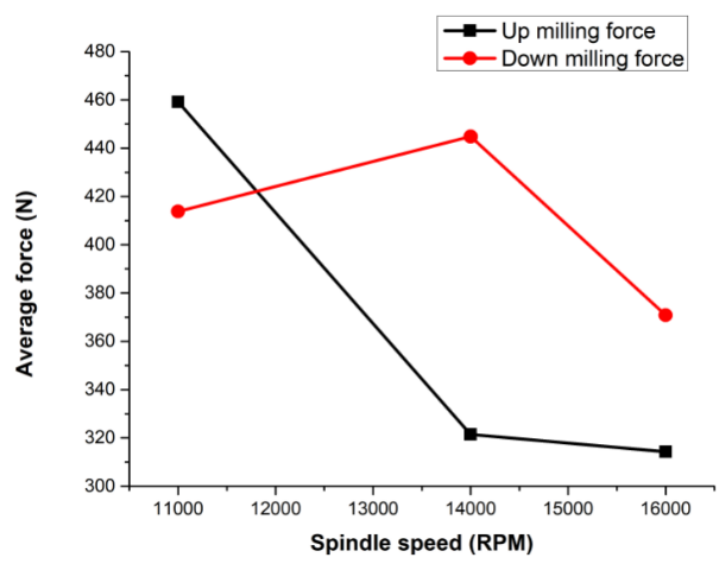

Fig. 7: Comparison of spindle speed parameter caused force variation in up and down milling.

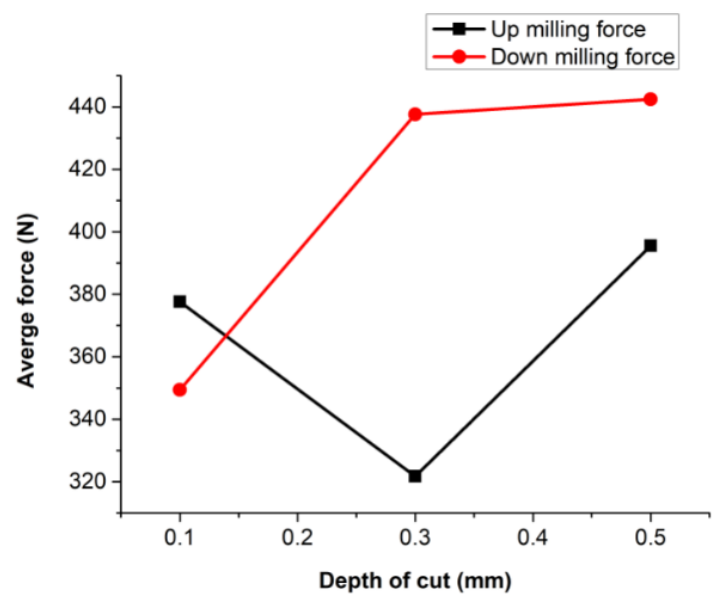

Fig. 8: Comparison of depth of cut parameter caused force variation in up and down milling.
According to the analyzed milling force data result. Figure 7 ,figure 8 and figure 9 are drawn. It can be concluded that accompanying with the rise of milling speed, depth of cut and width of cut, average up milling force initially higher than average down milling force, then the force could get an abrupt turn and became lower than down milling force. In this orthogonal experiment, comparing with other values of spindle speed, $16000 \mathrm{rpm}$ is suitable for up milling and down milling. When the depth of cut reaches $0.3 \mathrm{~mm}$, a low milling force could be acquired during up milling process and $0.1 \mathrm{~mm}$ is suitable for down milling process. When it comes to width of cut, both up and down milling force reaches its lowest point when depth of cut parameter was set to be $6 \mathrm{~mm}$. So, the suitable parameters for up milling are spindle speed $16000 \mathrm{rpm}$, depth of cut $0.3 \mathrm{~mm}$ and width of cut $6 \mathrm{~mm}$ and spindle speed $16000 \mathrm{rpm}$, depth of cut $0.3 \mathrm{~mm}$ and width of cut $6 \mathrm{~mm}$ for down milling process.

Tab. 6: Intuitive analysis of up milling result.

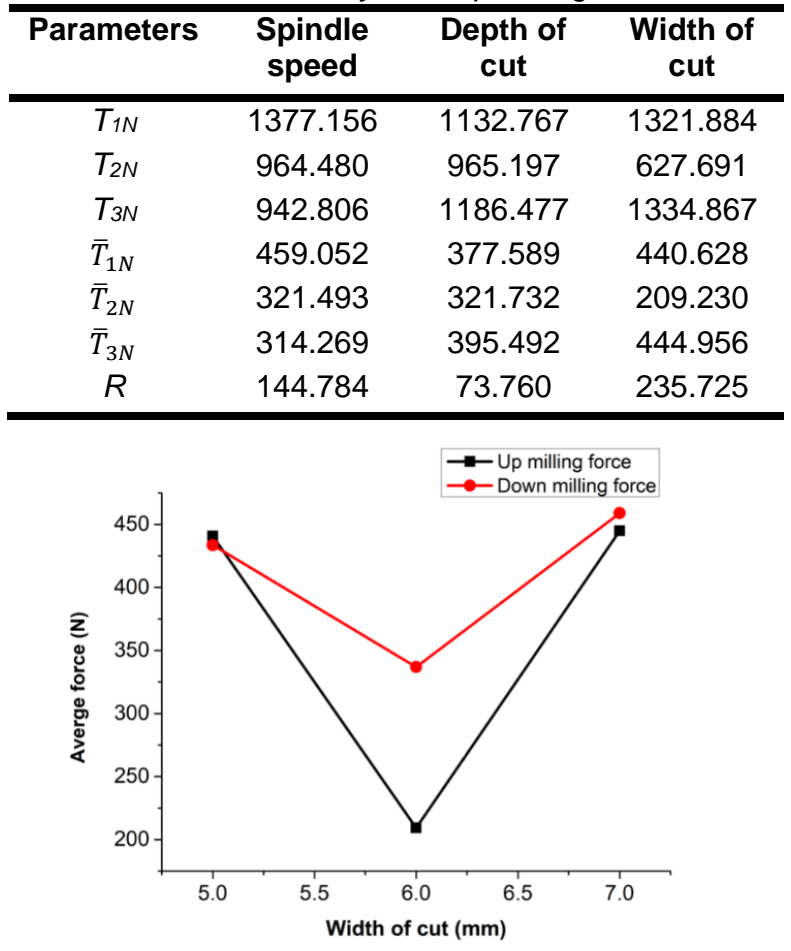

Fig. 9: Comparison of width of cut parameter caused force variation in up and down milling.

\subsection{Analysis of variance for milling force}

By intuitive analysis of up milling force, a rough understanding of different parameters influenced milling force can be acquired. However, the influence of each parameter on milling force cannot be directly found through intuitive analysis. So it is necessary to make variance analysis of different parameters.

Through calculating the sum of squares of deviation (SS), degree of freedom (DF), mean squared deviation (MS), $P$ value and $F$ value of different parameters. Which are listed as table 7 , the significance level of different parameter can be determined.

Tab. 7: Analysis of variance for up milling. 
According to the data, width of cut had significant influences on milling force $(P<0.05)$ in up milling process.

\subsection{Milling tool wear assessment}

For nickel-based alloy milling process, the chemical interaction between tool material and workpiece due to high temperature in the shear zone, intense friction at the toolworkpiece interface as well as work hardening of nickelbased alloy which all cause short tool life for most of milling tool materials. However, ceramic tool dry milling process are different from traditional milling process and the too wear was investigated through SEM photographs after the experiment. As figure 10 to figure 13 shows, it can be concluded that most tool wear during the process was abrasion wear, diffusion wear, adhesion wear and chipping at the tool edge.

Before the first use of monolithic SiAION ceramic end milling tool, EDS analysis on milling tool surface was used to detect the element composition of milling tool. The results are listed in figure 14 and table 8. Oxidation wear was found on milling tool surface through EDS analysis. After the milling experiment, EDS analysis on milling tool surface was also used for tool surface element analysis. As figure15 and table 9 shows, the weight of $O$ element was higher than the tool before use. So, it is obvious that oxidation wear of milling tool was happened during dry milling process. Other

\begin{tabular}{cccc}
\hline Parameters & $\begin{array}{c}\text { Spindle } \\
\text { speed }\end{array}$ & $\begin{array}{c}\text { Depth of } \\
\text { cut }\end{array}$ & Width of cut \\
\hline SS & 39936.870 & 8881.028 & 109130.098 \\
DF & 2.000 & 2.000 & 2.000 \\
MS & 19968.430 & 4440.514 & 54565.050 \\
F value & 7.217 & 1.605 & 19.721 \\
P value & 0.122 & 0.384 & 0.048 \\
\hline
\end{tabular}

new chemical elements were found on the tool surface, which is an evidence for adhesion wear on the milling tool surface.

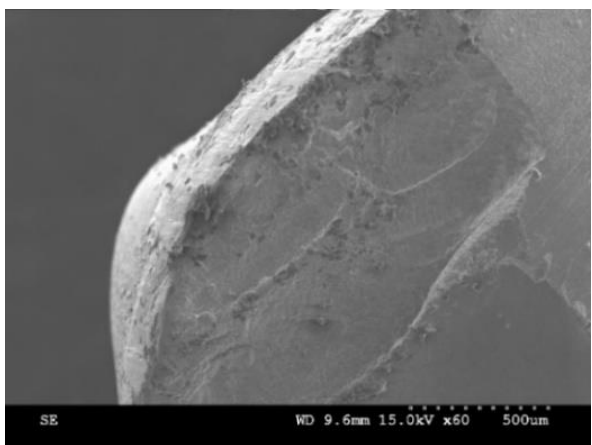

Fig. 10: Abrasion wear on tool edge.

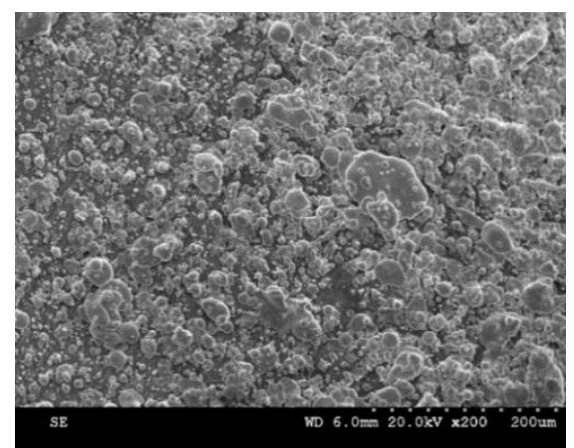

Fig. 11: Diffusion wear on tool edge.

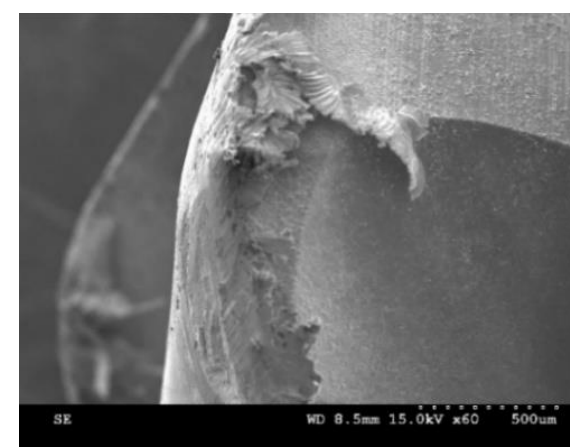

Fig. 12: Adhesion wear of workpiece on tool edge.

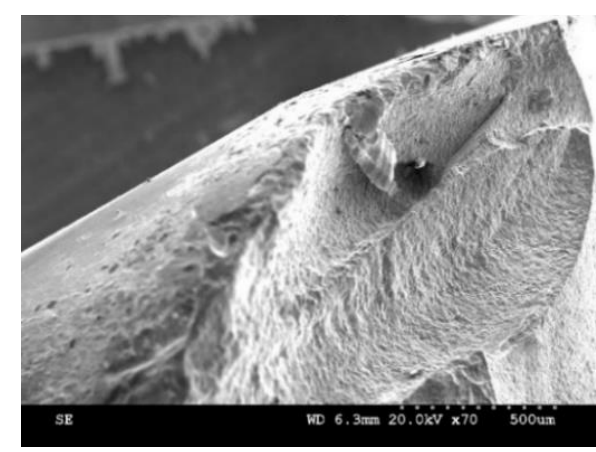

Fig. 13: Chipping on tool edge.

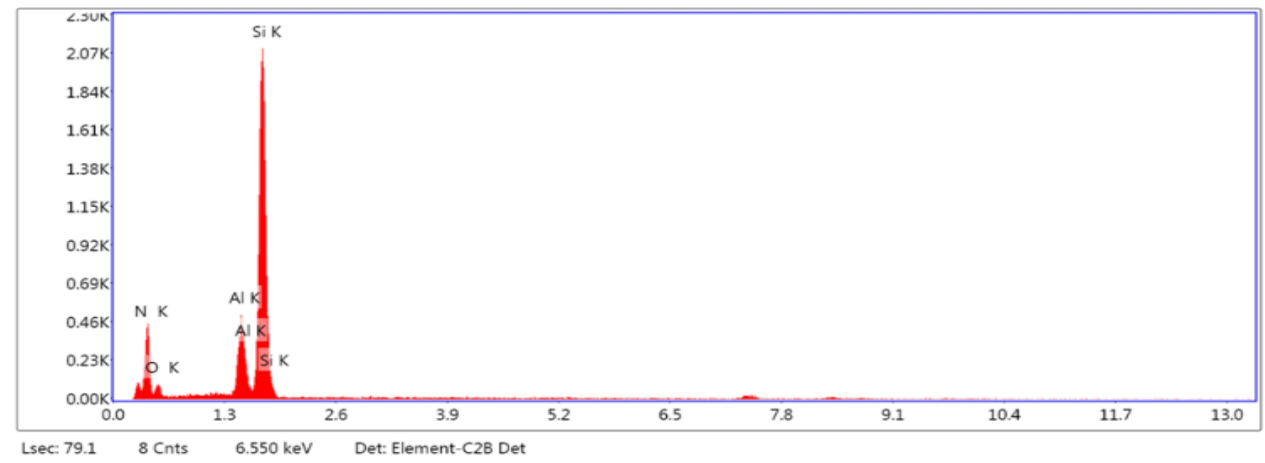

Fig. 14: EDS analysis result of new monolithic SiAION ceramic tool. 


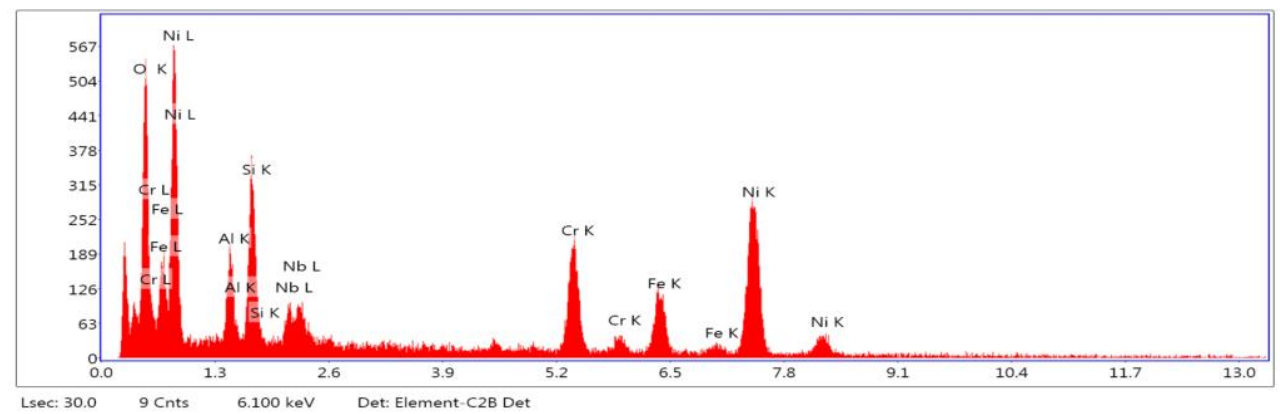

Fig. 15: EDS analysis result of used monolithic SiAION ceramic tool.

Tab. 8: Elemental composition of new monolithic SiAION ceramic tool.

\begin{tabular}{cc}
\hline Element & Weight \% \\
\hline $\mathrm{N}$ & 41.29 \\
$\mathrm{O}$ & 9.96 \\
$\mathrm{Al}$ & 8.41 \\
$\mathrm{Si}$ & 39.85 \\
\hline
\end{tabular}

Tab. 9: Elemental composition of used monolithic SiAION ceramic tool.

\begin{tabular}{cc}
\hline Element & Weight \% \\
\hline $\mathrm{O}$ & 11.16 \\
$\mathrm{Al}$ & 6.56 \\
$\mathrm{Si}$ & 9.70 \\
$\mathrm{Nb}$ & 3.90 \\
$\mathrm{Cr}$ & 13.79 \\
$\mathrm{Fe}$ & 11.13 \\
$\mathrm{Ni}$ & 43.75 \\
\hline
\end{tabular}

\section{CONCLUSION}

Compared with LAM process, these two methods both used milling heat caused material soften phenomenon as a method for acquiring lower cutting forces. But laser radiation can make cutting tool prone to wear and laser cost is higher when it was used under rough machining process. When using monolithic ceramic end mill tool dry milling ÉK61 nickel-based alloy, average temperature on shear zone can reach $1000^{\circ} \mathrm{C}$. The temperature exceeds the temperature of tensile and yield strength turning point, which makes the material softening phenomenon happened during dry milling process.

In orthogonal experiment, up milling seems more effective and can acquire a low force value compared with down milling when it is under high spindle speed condition. Because up milling process can cause more heat than down milling, so the material soften value can be higher than down milling. The width of cut is considered to have significant influence on milling force.

During dry milling process, the wear of monolithic ceramic end mill tool can be listed as adhesion wear, abrasion wear, oxidation wear and chipping of tool edge. The major reason for tool wear is the high temperature at shear zone.

\section{ACKNOWLEDGMENTS}

This work was supported by the National Natural Science Foundation of China (91860137), National Science and
Technology Major Project of the Ministry of Science and Technology of China (2017ZX04013-001).

\section{REFERENCES}

[Budak, E. 2005] Budak, E., et al. Maximizing Chatter Free Material Removal Rate in Milling through Optimal Selection of Axial and Radial Depth of Cut Pairs, CIRP Annals Manufacturing Technology,2005, Vol.54, No. 1, 353-356.

[Davis 2014] Davis, Danny R., et al. Monolithic ceramic end mill, U.S. Patent 11 Feb. 2014, No. 8,647,025.

[Leopardi G 2015] Leopardi G, Tagliaferri F, Rüger C, et al. Analysis of Laser Assisted Milling (LAM) of Inconel 718 with Ceramic Tools, Procedia Cirp, 2015, Vol 33, 514-519. [Evek 2018] Evek. Nickel-based alloy. < http://www.evek.biz/materials/splav-hn58mbyudek61.html> 2018

[Altintas $Y$ 2012] Altintas Y. Manufacturing automation: metal cutting mechanics, machine tool vibrations, and CNC design[J]. Industrial Robot, 2012, Vol 84.

[Maurel-Pantel A 2012] Maurel-Pantel A, Fontaine M, Thibaud S, et al. 3D FEM simulations of shoulder milling operations on a 304L stainless steel. Simulation Modelling Practice \& Theory, 2012, Vol 22, 13-27.

[Obikawa T 2015] Obikawa T, Yamaguchi M. Suppression of notch wear of a whisker reinforced ceramic tool in airjet-assisted high-speed machining of Inconel 718. Precision Engineering, 2015, 39:143-151. 
[Zhang 2012] Zhang, J. F. Li, and Y. W. Wang. Tool life and cutting forces in end milling Inconel 718 under dry and minimum quantity cooling lubrication cutting conditions. Journal of Cleaner Production 32. 81-87.

[Xavior M A 2017] Xavior M A, Manohar M,

Jeyapandiarajan $\mathrm{P}$, et al. Tool Wear Assessment During Machining of Inconel 718, Procedia Engineering, 2017, 174:1000-1008.

[Ezugwu 1998] Ezugwu, E. O., et al. The machinability of nickel-based alloys: a review. Journal of Materials Processing Technology, 1998, Vol 86, 1-16.

[lzhevskiy 2000] Izhevskiy, V. A., et al. Progress in SiAION ceramics. Journal of the European Ceramic Society, 2000, Vol.20, No.13,2275-2295.

[Kitagawa 1997] Kitagawa, et al. Temperature and wear of cutting tools in high-speed machining of Inconel 718 and Ti6Al6V2Sn. Wear, 1997, Vol.202, No.202, 142-148

[Klocke 2011] Klocke, Fritz. Manufacturing Processes 1. Springer Berlin, 2011. ISSN 1865-0899
[Komanduri 1988] Komanduri, et al. Advanced ceramic tool materials for machining. Sadhana,1988, Vol.13.1, No.2, 119-137.

[Liu 2005] Liu Wenqing. Design of Experiments, Tsinghua University Press, 2005. ISBN 9787302101413

[Schulz 1992] H.Schulz, High speed machining, Annals of the CIRP, 1992, Vol.41, 637-643.

[Altintas Y 1991] Altintas Y, Spence A, Tlusty J. End Milling Force Algorithms for CAD Systems. CIRP Annals Manufacturing Technology, 1991, 40(1):31-34.

[Sun 2010] Sun, et al. Thermally enhanced machining of hard-to-machine materials-A review. International Journal of Machine Tools \& Manufacture, 2010, Vol.50.No.8,663680.

[Third-wave Systems 2007] Third Wave AdvantEdge ${ }^{\mathrm{TM}}$. User's Manual Version 7.1 Third-wave Systems, USA, 2007.

[Zhu 2013] D.H. Zhu, et al. Tool wear characteristics in machining of nickel-based superalloys, International Journal of Machine Tools \& Manufacture, 2013, Vol 64, 6077 